\title{
Bung the gap: narrowing Global North - Global South bias in measuring academic excellence by weighting with academic capital
}

KOME - An International Journal of Pure Communication Inquiry Volume 7 Issue 2, p. 1-16. (C) The Author(s) 2019

Reprints and Permission: kome@komejournal.com Published by the Hungarian Communication Studies Association DOI: 10.17646/KOME.75672.40

\section{Marton Demeter}

\section{Department of Social Communication, National University of Public Service, HUNGARY}

\begin{abstract}
This paper presents an analysis of three modes of assessing academic scholars' productivity, based on their education history and their publication output. The sample consists of the career paths of 231 authors from the Global South that includes the places of their BA, MA and Ph.D. education and their production in terms of the number of their Scopus-indexed articles. The analysis found that there is no general rule determines that Global North education would result in higher productivity, and the paper will argue that favoring productive authors without Global North education would be not just ethical but also deliberately reasonable in the restricted sense of instrumental reason.
\end{abstract}

Keywords: Selection criteria, academic inequality, global power relations, Global South Global North bias, productivity assessment, academic capital

\section{Introduction}

Despite considerable modifications that occurred during the history of modern science in the last decades, the publish or perish paradigm remained inviolate (Erren, Shaw and Morfeld, 2016). One of the most important conditions for international success represented in tenure and hiring decisions is based on high-quality publications in leading peer-reviewed journals (Zdenek, 2018). One could presume that the more talented and hardworking a scholar is, the more publications of high quality she will have, but empirical data contradict to this assumption by presenting evidence on serious inequalities. The assumption would be, in the case of a sufficiently merit-based field, that talent and diligence will lead to research excellence which could be measured in publication output. Contrariwise, one could conclude from research excellence to the diligence and talent of the candidate. Some researchers add the role of good fortune (Frankl, 2017), but this current paper prefers to call it structural inequality.

Sociologists of science found that the world of the academy is full of invisible colleges (Price, 1965), and non-academic factors like geographical position, political and economic issues (Shenhav, 1986) or cultural and epistemic differences (Toth, 2012) play a crucial role in publication possibilities. Academic inequalities of these shorts divide the world of science into two domains: there are successful countries that have leading periodicals and many papers in them, and there are the so-called Matthew countries (Bonitz, Bruckner and Scharnhorst, 1997) 
that do not have highly visible journals, neither have they significant number of authors that publish in leading periodicals (Zanotto, Haeffner, and Guimaraes, 2016). The typical Matthew countries are those from the Global South (GS) including Africa, the developing Asia (China, India, Malaysia, just to mention the most important ones), South America, the Middle East and Eastern Europe (with Russia), while the winner countries are those from the Global North (GN) including developed Asia (Japan, Korea, Taiwan, and Singapore), North America, Israel and Western Europe (Demeter, 2017; Lauf, 2005). Scholars from Matthew countries get, typically, fewer citations for their articles, their odds for publishing in top-tier international journals is far below than those of their GN colleagues, not to mention their prospects of being a bestseller, academic authors. As Heilbron and his colleagues put it, "virtually all of the most cited scholars in the social and human sciences were born and have worked in western countries" (Heilbron et al, 2018, p. 7). Even the name Matthew-country refers to the so-called rich get richer or Matthew-effect that, as a paraphrase for the Biblical verse in the gospel of Matthew ("for to every one who has will more be given, and he will have abundance; but from him who has not, even what he has will be taken away") says that GN authors will be more cited than their GS colleagues irrespectively of the fact that they were published in the same journal and in the very same issue. The phenomenon of this serious inequality between central and peripheral regions of academe are well known, and often treated as trivial and unproblematic:

The current status of the academic communities at the center is, at least for the immediate future, an immutable reality of the world knowledge system. Universities in developing countries and their academic communities must function in the unequal world of centers and peripheries. Peripherality does not mean that academics in the developing world cannot do creative scientific or intellectual work, or that they are forever relegated to a subordinate status in academe. It does mean that they will seldom be at the frontiers of world science and will not share in the control over the main levers of academic power worldwide. (Altbach, 2003, p. 4.)

Current research also shows that inequalities between the publication achievement of the GN and the GS are much bigger in social sciences and in humanities than in the case of natural sciences, life sciences or mathematics (Gumpenberger et al, 2016; Moody, 2004). It is not surprising, however, if we consider that epistemic, cultural and regional differences - not to mention language issues - matter mostly in social sciences and in humanities, while they are not quite as important in mathematics, physics or life sciences. A recent study shows that amongst social sciences, the GN - GS inequality (in terms of publication biases) is the most significant in the case of communication studies There is less GN/GS bias in philosophy and in hard sciences, and the most balanced picture could be found in the case of engineering, where the aforementioned cultural, epistemic and regional differences do not play determining roles. Engineering is the only discipline in Scopus, where not a GN region, but China leads the global academic field by delivering more than one-third of the total publication output. China is followed by the US (13\%), India (6\%), Korea (5\%), Japan (5\%) and the UK (5\%). As contrasted with engineering, the $\mathrm{GN}$ is the absolute leader of science output in both natural and hard sciences with the difference that there is a greater Western European contribution in hard sciences than in the soft sciences where the United States is the absolute 'winner takes all' country (Demeter, 2018; 2019).

In order to raise the visibility of their scientific achievements, GS scholars often try to win GN affiliation (Lee and Kuzhabekova, 2017). Mobility, that is, being educated or work abroad raises the symbolic or academic capital of researchers (Bourdieu, 1988; 1998; 2004) in a great extent, while immobility often results in narrowed career paths. The motivations behind 
mobility include simply economic features like higher salary or better material-technical conditions, but research shows that the promotion of scientific visibility - growth in publication output, co-authored international publications or the increase of citation indices - also play a very important role (Asheulova and Dushina, 2014; Aksnes et al, 2013). Since mobility is the most important factor when GS academics wish to raise their academic capital, it is expected that more mobile authors will collect more capital. Amongst the most obvious examples of "entry-level" (Bourdieu, 2004) academic capital like BA, MA or PhD degrees accomplished in the GN, scientists could collect advanced types of capital in the form of GN postdoctoral research experience, international grants, GN affiliations (Shen et al, 2018) and, mostly, publications in leading periodicals (Cole, 1967; Hanssen et al, 2017). But, as this paper will show later, GS authors face serious disadvantages when they apply for positions at GN institutions, since GN education experience often goes for academic capital in itself, and GN education is presumably added to the publication output, too. With this "double counting", GS candidates must be extraordinary productive in order to be taken into account in terms of hiring, because they have to compensate for their GS education. This present paper will show that academic capital (GN education) and academic production (publication output) could be calculated in at least three different ways, and these different ways of calculations significantly modify the ranks of applicants. This article will also make the case for using the GS-weighted calculation which favors the most productive GS educated candidates against their equally (or worse) productive GN educated competitors. But first of all, the analysis has to differentiate academic capital from academic production to make later calculations conceptually clear.

Bourdieu's notion of capital could be roughly conceived as the extension of the economic sense of the concept, since

Bourdieu's purpose is to extend the sense of the term "capital" by employing it in a wider system of exchanges whereby assets of different kinds are transformed and exchanged within complex networks or circuits within and across different fields. He is attempting to relocate the narrow instance of mercantile exchange away from economics into wider anthropology of cultural exchanges and valuations of which the economic is only one (though the most fundamental) type. It is important to note, however, that other forms of capital such as cultural and social can be seen as "transubstantiated" forms of economic capital. (Grenfell, 2008, p. 102).

Thus, academic capital is a symbolic capital that could be accumulated in the form of certifications, degrees, fellowships, research grants and work experience. Academic capital that has been collected in the top of the hierarchy (typically, in the US and other English-speaking countries) is much more valuable than those collected in rather peripheral countries (Bauder, 2015; Bauder et al, 2017). Thus, academic capital is generally measured in terms of BA, MA and Ph.D. certifications from GN countries. As opposed to academic capital, academic production is measured by the number of high-quality publications. Since, especially in social sciences and humanities, leading journals are published at the GN almost without exception (Altbach, 2003; Demeter, 2019), academic production refers to the number of GN publications generally indexed in prestigious international science databases like Scopus or Web of Science SSCI list (Astaneh and Masoumi, 2017). But, as the paper will argue later, academic capital should be allegedly incorporated in academic production, because the main role of every capital (including academic capital) is to boost production (Johnston and Schluter (2017). Thus, a candidate A with GS education (less capital) who has the same production as her competitor B with GN education (more capital) is much more productive than candidate $\mathrm{B}$, since the former made the same production with less capital. Otherwise, one should say that GN education could 
not be conceived as academic capital since it does not boost the productivity of an equally productive candidate. Based on the above-mentioned assumptions this paper argues that productivity is the quotient of production (measured in the number of high-quality articles) and capital (measured in GN degrees and experience).

$$
\text { i. } \quad \text { Productivity }=\frac{\text { Production (number of articles })}{\text { Academic capital }(\text { GN degrees and experience })+1}
$$

However sensible is that selection committees should use the above-mentioned formula when assessing candidates' merits in most cases, the rather opposite calculation is being used when GN education is added as a surplus to measured production (Cook, 2009; Evers et al, 2005). It is a fairly detrimental way of calculating productivity since it is well known that not education in itself but rather pre-selection productivity is the main factor in predicting future publication success (Kaiser and Pratt, 2016). Thus, the best predictor of future success is a prior success in publishing academic research - and not education per se. As the same authors put it, "like it or not, peer-reviewed publications are the 'currency of the business,' and they tend to dominate articles about faculty rankings more than anything else." (Kaiser and Pratt, 2016, p. 439). Other authors like Génova, Astudillo, and Fraga (2015) or Kekale (2018) also argue that published academic papers are, in principle, the currency of science.

Since hiring new fellows is a serious investment, "it is not surprising that the topic of employee recruitment has attracted considerable attention. In fact, as employers are becoming more strategic with regard to talent management, the importance attached to recruitment has increased" (Schmitt, 2012, p. 68). Herschberg, Benschop, and Bring (2018) argue that excellence became the main criterion in staff selection decisions, and they also state that this research excellence could and should be gauged in an objective, neutral and merit-based manner. But the same authors also put that only a few selection committee members question traditional selection criteria, and with this mentality, they limit the pool of candidates - and it could lead to the exclusion of many talented scholars. For example, international experience is usually narrowed to those attained in a limited number of countries, so mostly the Englishspeaking research universities of the GN are valued. Since this process premiates GN educated candidates (without reference to their production) it often excludes more productive but GS educated applicants (Altbach, 2004). Selection committee members could make inferences even about the candidates' level of English, which can put applicants of certain nationalities at more of a disadvantage than others (Herschberg, Benschop and Bring, 2018). Behtoui and Leivistad (2019) also observed that GS applicants are more likely to remain unemployed, and even if they are employed, they would get lower positions than their GN peers. This all abovementioned phenomena causes serious disadvantages to not just GS academics but to science itself, because they make tough barriers to the flow of international talent.

Based on current research on this topic, this paper assumes that GN educated candidates are unjustly favored over their GS educated competitors if selection committees will overrate their productivity based on their GN academic capital. Thus the hypothesis of the article is that

H1 if selection committees would replace the GN-weighted calculation with its GS-weighted variant, the rank of candidates would significantly transform and it would give a chance to very productive GS educated applicants.

\section{Methods}

Since former research shows that the most extreme bias towards academics from the GS could be found in communication studies (Demeter, 2019), this present research chose this particular 
field for the analysis of publication success. First, all the communication journals from the first quartile (Q1) of Thomson Reuters' Web of Science SSCI list were selected. With this, the sample consists of 19 periodicals (Table 1). Second, national diversity measures for each journal from 2013 to 2017 were made. National diversity measure shows the diversity of a given periodical in terms of the percentage of authors with affiliations of different countries or, in this present example, of different world regions. Only research papers were analyzed $(\mathrm{n}=$ 3910) since they are usually considered as the most valuable publications in terms of science output. Third, those articles that had been published, or at least co-authored by GS author(s) were systematically selected. As a result, the sample consisted of 263 GS papers. A GS paper means an article that has been submitted from a GS institution and this information was indicated on the author info part of the paper. Therefore, the labels 'GS author' and 'GS paper' refer to the nationality of the submission's affiliation only, not to the country of origin of the corresponding author(s). As a result, 426 (co)authors from GS affiliations were selected. As a next step, the cv-s of each author were selected from their official academic sites (official site of their departments or institutions, academic social media sites like Academia.edu, Researchgate, LinkedIn, Mendeley and Escavador). Then the so-called academic milestones of the authors considered as science capital (BA, MA, and Ph.D. degrees) and the number of their Scopus-indexed articles considered as science production were recorded. The science production of an author refers to the total number of their Scopus indexed articles so it is not restricted to the analyzed time period. It means that authors with science production $=1$ published only one Scopus indexed article in their course of academic life. Since only clear and assured data were registered, those authors with missing information were deleted. As a result, our sample consists of 315 GS authors with complete and appropriate data. In some cases ( $\mathrm{n}=$ 14) the list has the same author twice, but in these cases, their productivity indices were listed only once. So, for example, authors with 2 occurrences were registered only once with their corresponding productivity indices. In the course of this empirical research, the analysts aimed to work with as accurate data as it was possible, so only certified data regarding the career paths of the different authors were recorded. If it was possible, the official web page of the author's affiliation was used. If it was not possible, the author's cv was found on professional academic social media sites like ResearchGate, Academia.edu, LinkedIn or Mendeley. If the data was defecting, unclear or the CV of the author was completely missing, the corresponding author was clustered to the N/A category. As a result, 110 authors (26\% of the original sample) was registered without appropriate data. It means that the current analysis is representative to only those authors with clear and certified data. It can be assumed, however, that authors with missing resumes are not on the top of the discipline, in other words, they have, presumably, low publication output irrespectively from their education history. Consequently, their missing or presence on the lists of this paper would not likely to affect the top of the rankings.

This research aimed to show power relations in the top of the field, that is why the most selective Web of Science was used instead of Scopus. But the analysis aimed to be also detailed, that is why Scopus was used when calculating the number of articles of a given individual. In other words, journal selection was conducted in regard to prestige (Web of Science), and publication measurement was conducted in regard to a more detailed picture since the average number of Scopus indexed articles is much greater than that of the Web of Science indexed articles.

Considering the place of the BA, MA and Ph.D. education of the authors as science capital and their numbers of Scopus-indexed articles as science production, different measurements regarding their weighted productivity were taken. Their normal productivity (NORM) is equal with their production: in this case, education was considered as irrelevant as regards the measured productivity, or, more precisely, as incorporated in the production. Their GNweighted productivity has been calculated as follows. Each type of science capital (BA, MA, 
and Ph.D.) which has been earned at a GN university gives $10 \%$ (in case of GN10) or 20\% (in case of GN20) surplus to normal productivity. Thus, for example, if an author A has 10 Scopusindexed articles and she has a GS BA and a GS MA, then her GN10 and GN20 will be 12 and 14 accordingly $(10 \times(1+0.1+0.1))$ and $(10 \times(1+0.2+0.2))$. On the contrary, the GSweighted productivity index premiates GS science capital, so GS BA, MA, and Ph.D. will increase the normal productivity of a given author. Accordingly, if an author B has 10 Scopusindexed articles and she has GS BA, MA and PhD degrees, then her GS10 and GS20 indices will be $13(10 \times(1+0.1+0.1+0.1))$ and $16(10 \times(1+0.2+0.2+0.2)$, see Table 1$)$. With this, she could overtake many of her competitors with a similar number of published papers but GN degrees. This paper will cover the significance of these different calculations in details in the discussion part.

Table 1 Calculations for different measurements. Percentages should be added together and then it should be multiplied by the number of articles.

\begin{tabular}{|l|l|l|l|l|l|l|}
\hline & GN BA & GN MA & GN PhD & GS BA & GS MA & GS PhD \\
\hline NORM & 0 & 0 & 0 & 0 & 0 & 0 \\
\hline GN10 & $+10 \%$ & $+10 \%$ & $+10 \%$ & 0 & 0 & 0 \\
\hline GN20 & $+20 \%$ & $+20 \%$ & $+20 \%$ & 0 & 0 & 0 \\
\hline GS10 & 0 & 0 & 0 & $+10 \%$ & $+10 \%$ & $+10 \%$ \\
\hline GS20 & 0 & 0 & 0 & $+20 \%$ & $+20 \%$ & $+20 \%$ \\
\hline
\end{tabular}

\section{Results}

Table 2 shows the analyzed journals and the amount of the GS articles in them. As it can be seen, generally speaking, the GS content is under 10 percent almost everywhere, and it is not unusual that a journal has less than 5 percent of GS articles.

Table 2 The analyzed sample of WoS SSCI journals with the number and percentages of GS articles and the science capital of the GS authors

\begin{tabular}{|c|c|c|c|c|c|c|}
\hline Title (WoS SSCI Q1) & $\begin{array}{l}\text { total articles } \\
\text { (n) }\end{array}$ & $\begin{array}{l}\text { GS } \\
(\mathbf{n})\end{array}$ & GS \% & $\begin{array}{l}\text { GN BA } \\
\%\end{array}$ & $\begin{array}{l}\text { GN MA } \\
\%\end{array}$ & $\begin{array}{l}\text { GN PhD } \\
\%\end{array}$ \\
\hline New Media \& Society & 475 & 32 & 6,7 & 20 & 66 & 71 \\
\hline Journal of Computer-Mediated Communication & 173 & 17 & 9,8 & 9 & 55 & 86 \\
\hline Journal of Communication & 268 & 15 & 5,5 & 11 & 78 & 89 \\
\hline Media Psychology & 114 & 5 & 4,3 & 33 & 60 & 73 \\
\hline Communication Research & 223 & 5 & 2,2 & 25 & 25 & 50 \\
\hline Journal of Advertising & 182 & 11 & 6 & 30 & 40 & 60 \\
\hline Communication Theory & 110 & 4 & 3,6 & 100 & 100 & 100 \\
\hline Information, Communication \& Society & 431 & 24 & 5,5 & 17 & 22 & 28 \\
\hline Public Understanding of Science & 336 & 26 & 7,7 & 11 & 28 & 50 \\
\hline Political Communication & 149 & 2 & 1,3 & 100 & 100 & 100 \\
\hline International Journal of Advertising & 191 & 17 & 8,9 & 15 & 50 & 55 \\
\hline Comunicar & 201 & 53 & 26 & 4 & 12 & 26 \\
\hline IEEE Transactions of Professional Communication & 93 & 11 & 11 & 17 & 53 & 53 \\
\hline
\end{tabular}


Technical Communication

\begin{tabular}{rrrrrr}
77 & 3 & 3,8 & 0 & 0 & 0 \\
189 & 6 & 3,1 & 30 & 55 & 30 \\
306 & 22 & 7,1 & 19 & 41 & 32 \\
103 & 3 & 2,9 & 33 & 66 & 66 \\
169 & 7 & 4,1 & 14 & 29 & 86 \\
120 & 0 & 0 & 0 & 0 & 0 \\
& & & & & \\
$\mathbf{3 9 1 0}$ & $\mathbf{2 6 3}$ & $\mathbf{6 , 7}$ & $\mathbf{2 7}$ & $\mathbf{4 9}$ & $\mathbf{5 9}$ \\
\hline
\end{tabular}

As demonstrated here, even those from the GS who succeed in publishing in leading periodicals had their education - at least partly - in the GN. Thus $27 \%$ of GS authors had their BA from GN universities, and this amount increases to $49 \%$ on MA and $59 \%$ on the PhD level. There are five periodicals in which more than $85 \%$ of the GS authors have their Ph.D. from GN universities, while two journals - Communication Theory and Political Communication - have exclusively GN educated GS authors who have BA, MA and Ph.D. degrees from the West.

When the analysis is looking for possible correlations between GN education and the success in publication output it founds that there were no significant correlations in any directions. The results were $\mathrm{r}=-0.012$ for GN BA and productivity at $\mathrm{p}<0.05$ (P-value $=$ $0.856), \mathrm{r}=0.057$ for GN MA and productivity at $\mathrm{p}<0.05$ (P-value $=0.388), \mathrm{r}=0.077$ for $\mathrm{GN}$ $\mathrm{PhD}$ and productivity at $\mathrm{p}<0.05(\mathrm{P}$-value $=0.243)$, and $\mathrm{r}=0.053$ for $\mathrm{GN}$ " $\mathrm{BA}+\mathrm{MA}+\mathrm{PhD}$ " and productivity at $\mathrm{p}<0.05(\mathrm{P}$-value $=0.417)$. In all cases, the positive correlation between the GN education of GS scholars and their future success in terms of publication output was not significant (or even slightly negative): nor BA, MA or Ph.D. degrees, neither their combination results in a greater number of Scopus-indexed articles. These results mean that there is no general rule that determinates that GN education (in any level) would necessarily boost someone's science output in terms of the number of Scopus-indexed articles. For this reason, the analysis should turn the career trajectories of the individual researchers.

Figure 1 shows the science production measures of the normal calculation (NORM). The horizontal axis shows the number of authors with the appropriate production, while the vertical axis shows the production (the number of Scopus-indexed articles). It can be seen that this is a consistently decreasing curve with a small number of authors with extraordinary productivity and an abundance of authors with 1-5 papers. The productivity of a given author is the same as their production numbers in NORM since this is a non-weighted calculation. This paper will use NORM as a reference for the weighted calculations. 
Fig 1 The non-weighted productivity indices of GS authors (NORM)

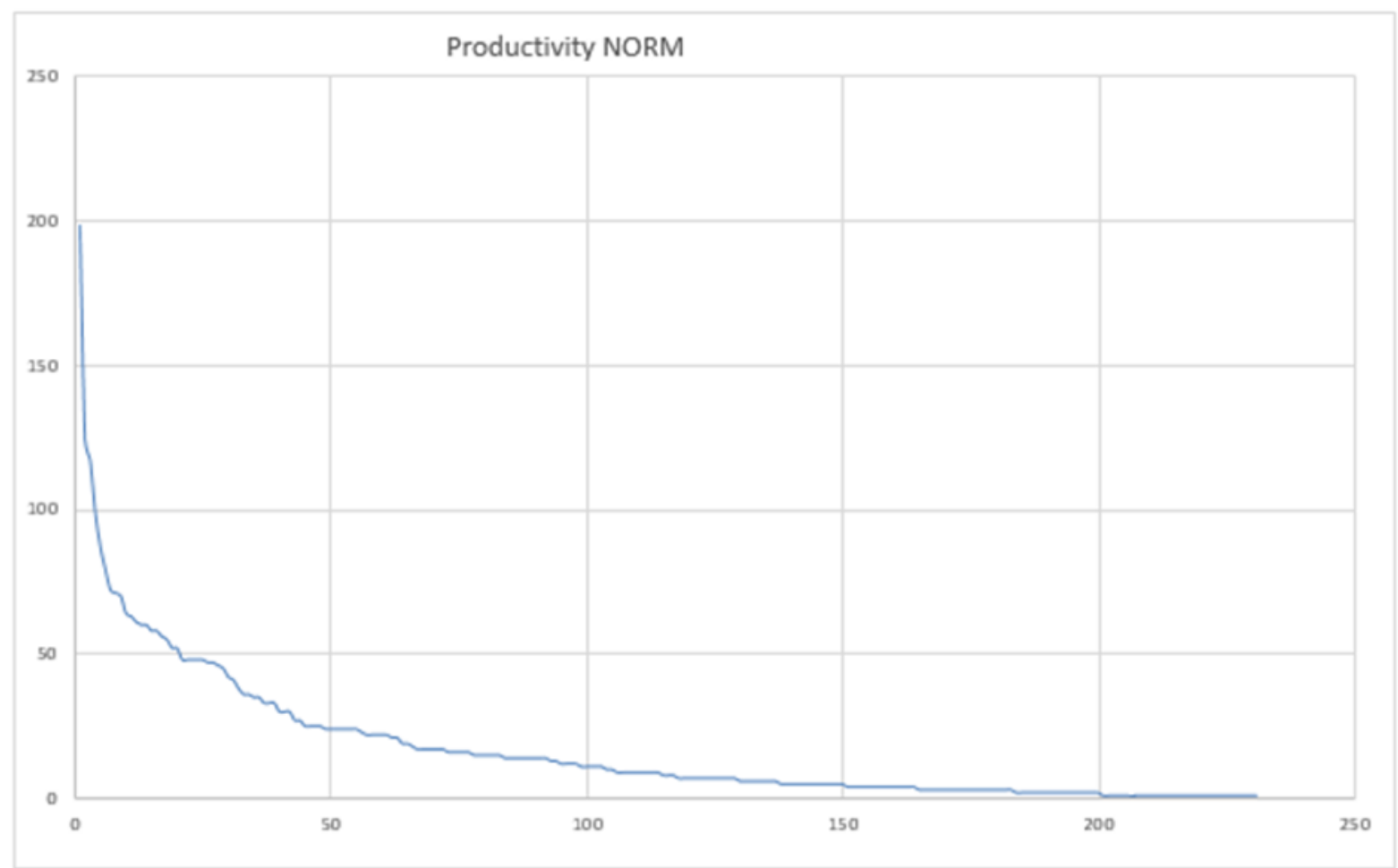

Figure 2 shows the modification of NORM when the calculation starts to weight productivity indices with GN capital. It means that authors with GN education could overtake authors with the same publication output but without the corresponding GN capital. The maximum amount of the overtaking depends on the weighting percentage: with $+10 \%$ / capital type, a maximum jump of 12 places were found, while with $+20 \%$ / capital type it was 21 places. It means, for example, that after a GN20 weighting, candidate B on the 31st place of the NORMAL shortlist could actually overtake candidate A who was on the $10^{\text {th }}$ place in spite of the fact that candidate A has much more Scopus-indexed publications. Waves on the curve refer to position shifts in favor of candidates with GN capital. 
Fig 2 The weighted productivity indices of GS authors (GN10 and GN20)
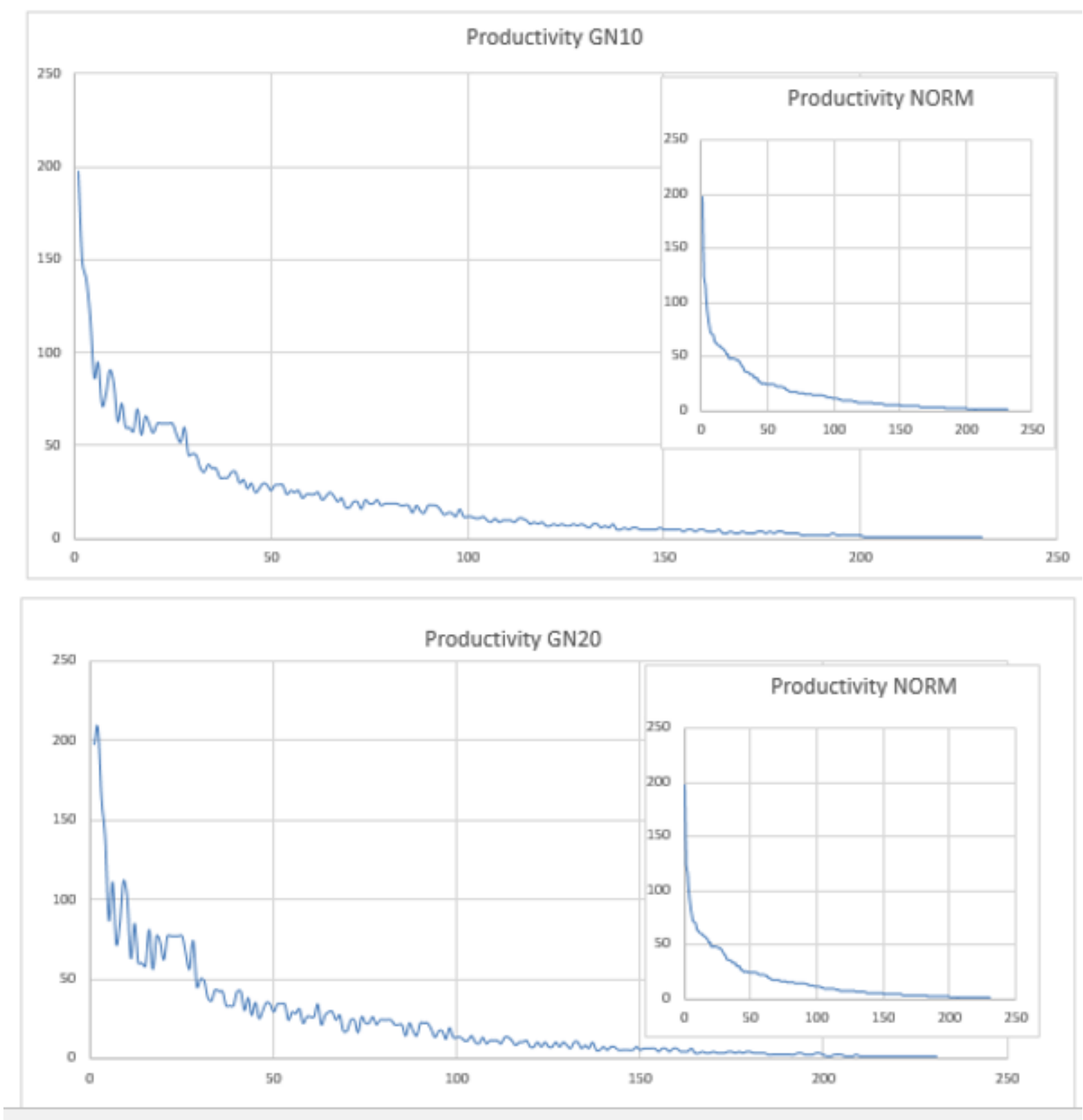

By contrast, Fig 3 shows the modification of NORM when the calculation starts to weight productivity indices with GS capital. It means that authors with GS education could overtake authors with the same publication output but without the corresponding GS capital. The maximum amount of the overtaking depends on the weighting percentage: with $+10 \%$ / capital type, a maximum jump of 11 places were found, while with $+20 \%$ / capital type it was 22 places. It means, for example, that after a GS20 weighting, candidate B on the 50th place of the NORM shortlist could actually overtake candidate A who was on the 29th place in spite of the fact that candidate A has much more Scopus-indexed publications. Waves on the curve refer to position shifts in favor of candidates with GS capital. 
Fig 3 The weighted productivity indices of GS authors (GS10 and GS20)
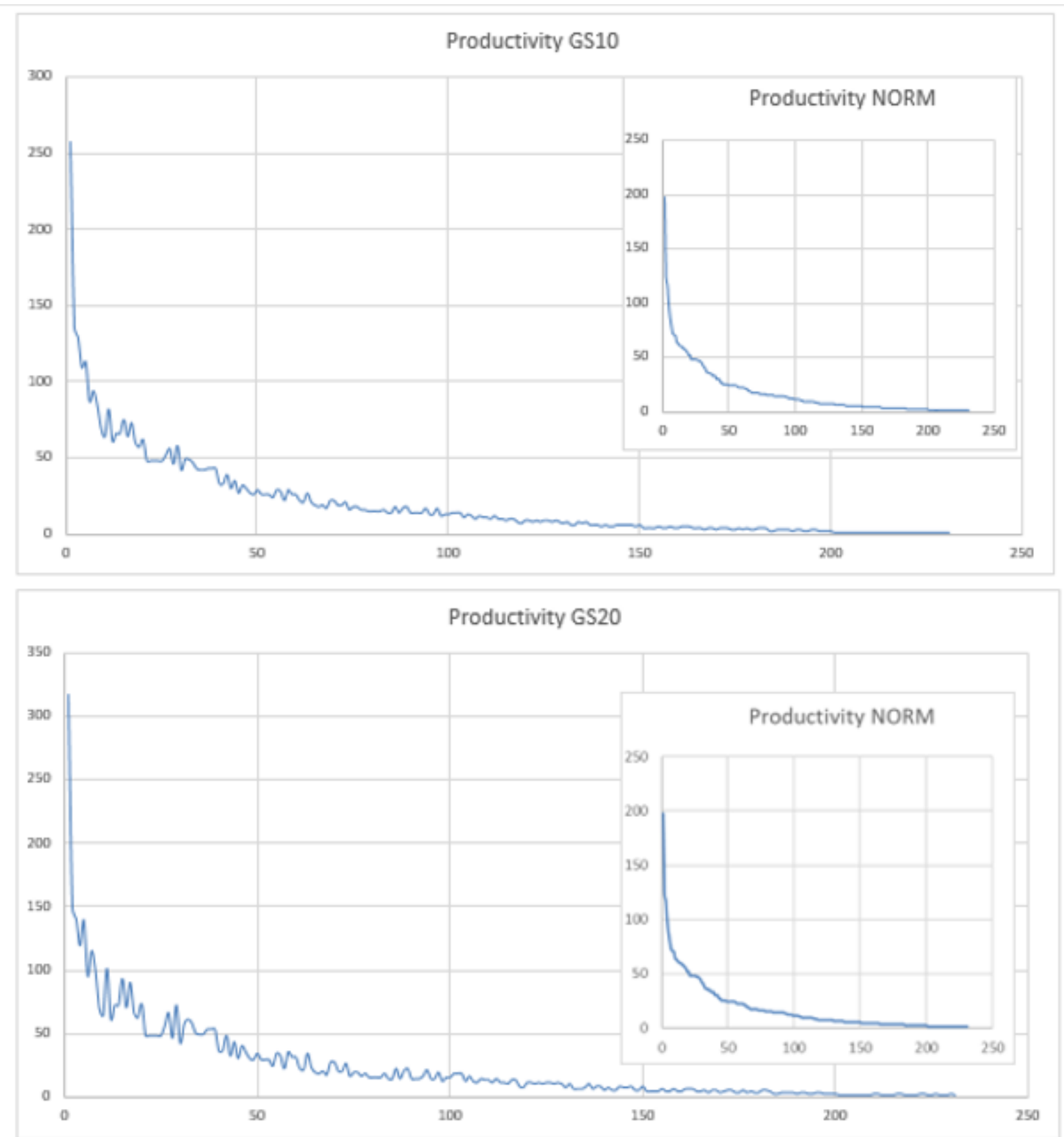

As demonstrated here in the cases of all weighted calculations, position shifting was the most characteristic for the most competitive positions. It means that weighting with education as science capital can be meaningful and even determining in the case of the high performing academics, and its significance is only marginal if not indifferent for their less excellent peers. Finally, when the calculation correlates the weighted calculation to not the normal form (NORM) but to each other (GN to GS calculations), very significant modifications could be seen in the ranking of the candidates. Fig 4 shows the most extreme setting when GN20 to GS20 were compared. Data show that position changes are extraordinary frequent when GN20 calculation was commuted to GS20. 
Fig 4 The weighted productivity indices of the top 100 GS authors (GN20 vs GS20)

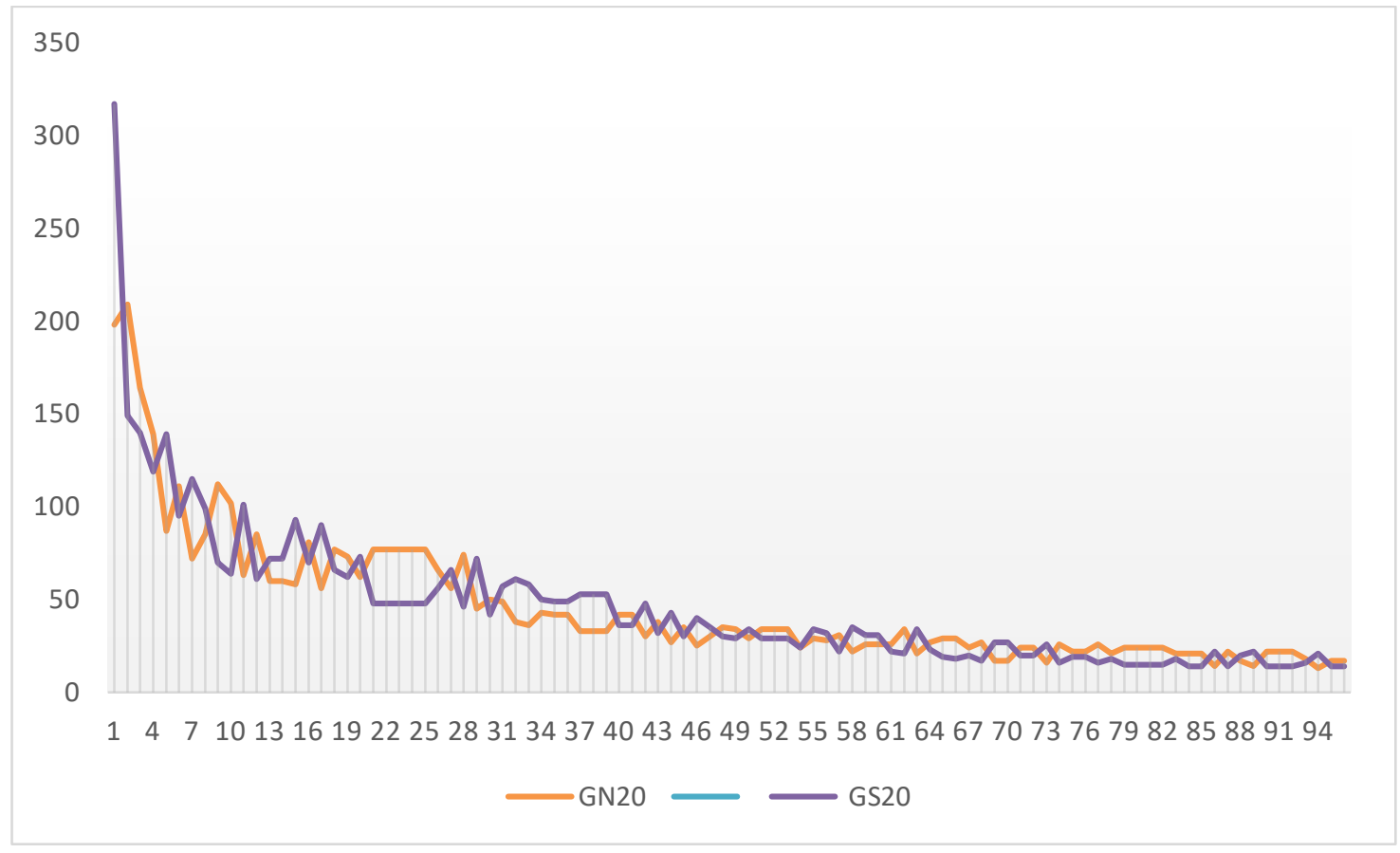

These results definitely confirm the hypothesis that if the GN-weighted calculation had been replaced with its GS-weighted variant, the rank of candidates would significantly transform and it will give a chance to very productive GS educated applicants (H1). It can be seen in Fig 4 that there are several position changes on the top 100 list of applicants when the weighting was changed, and the most dramatic changes occur at the top of the ranking. While the verification of $\mathrm{H} 1$ is not an empirical proof in a sense that it does not prove that the modified list is better in an objective sense, this paper has two arguments for the assumption that this new, modified list where GS education is favored is more reasonable than the opposite that shows favor to GN educated scholars. First, since this current paper holds the view that GN education already influences scientific production positively, therefore it should not be counted apart. Second, one could also suggest within reason that GS authors with the same publication output are more prosperous (in the sense of future productivity) than GN educated competitors with the same productivity since they made the same production with less capital. A GN affiliation would boost the productivity of a GS educated candidate in a much bigger extent than that of a GN educated academic because this latter is already familiar with GN knowledge (GN academic capital).

\section{Discussion}

Data show that there is no general rule suggesting that GN education will necessarily lead to better performance in terms of science production. In spite of this, in most cases, excellence in education (in the form of GN BA, MA or Ph.D.) serves as a surplus capital in the eyes of selection committee members. To assess the possible roles that capital play in the production of academics, this paper should briefly highlight the differences between academic capital and academic production again. In accordance with the Bourdieusian conception, capital is some implementation of knowledge which could contribute to the publication success of a given academic. In this current case, if GN capital (in the form of BA, MA and Ph.D. degrees from GN universities) do contribute to publication success, then it should be manifested in the greater 
number of Scopus-indexed articles. Nevertheless, as it could be seen from the results, GN education of GS scholars does not lead automatically to a boosting in their science publication output.

So one can ask: in what sense could be said that GN education should be conceived as academic capital and should be added to the scientific production of a given candidate as a surplus? Why research committees have to overvalue candidates with elite degrees when their science output is not better than their peer candidates with GS education? In accordance with the three variations of measurement of this paper (NORM, GN+10/20, GS+10/20), three arguments could be constructed regarding the assessment of science production.

The first and simplest argument is that one should not count BA, MA and Ph.D. degrees at all, because they are either incorporated in science production in form of a higher number of articles or they are irrelevant regarding science output. The normal measurement (NORM) shows a calculation of this kind, where the productivity of the candidates equals the number of their Scopus-indexed articles irrespectively from their education history. In this case, selection committees would select the most productive candidates while neglecting their education history. This type of calculation could assume that GN education is a form of academic capital, but it also assumes that it should be incorporated into the publication output. With this, the calculation hypothesizes that the productivity of author A with GN education would be lower without her GN education, and, consequently, it should also assume that author B with GS education might perform better if she had a GN education instead. Without the abovementioned assumptions, one should suppose that education does not matter at all, which is counterintuitive and contradict to our conception of academic capital.

In this stage of the argumentation, the paper should refer again to the connections between academic capital, production, and productivity. In most cases, capital is conceived as means of tools, knowledge, and courses of action that positively effects on productivity. But capital is always expensive to accumulate, in terms of both time and financial sources. One might ask which worker is more productive: the one producing a given amount of product with more capital or the one producing the same amount of product with less capital? It is beyond question, that the second one, so, in the case of equal production, workers with less capital are more productive than those with more capital. This finding will be very important later when the assessment of the calculation methods will be taken.

The second and most commonly used calculation is when GN education is added to the production of the candidate as a surplus of academic capital (GN10 and GN20). Since most selection committees prefer candidates with GN education history, one can hypothesize that this is the most typical way of calculating the productivity or the general academic value of a candidate. Of course, the exact algorithms by which selection committee members weight the productivity of the candidates are unknown, but data show that even as little as $10 \%$ surplus per GN degrees could lead to significant differences regarding the positions of the candidates. Calculations of this kind would eventuate a ranking of applicants where GN educated candidates with less publication success could easily take the lead over GS authors with significantly more publications. As a foundational idea behind this calculation one could find the assumption that GN education is a very important academic capital, so GN experience has to be added to the publication output as a surplus, as an extra value of a given candidate's productivity. But one can easily contradict to the plausibility of this method. Suppose that GN education could be conceived as academic capital. Then, it means better training, better knowledge transmission and it also includes acquiring better familiarity with research methods, academic writing and publication habits. If GN education is a sort of advanced guarantee for research excellence, then one could assume that candidates with GN education will perform better than their GS educated peers. In this case, their GN academic capital will be expressed in their publication output; not as a surplus that should be added to their productivity indices 
but as one of the causes of these attractive indices. If GN education is capital then a candidate A with 10 Scopus-indexed articles is someone who published 10 articles owing the fact, at least partly, that she has been educated in a GN institution. When selection committees add extra points to her production (expressed in the number of her articles) then they count the very same thing (her GN education) twice, which is not just unethical but deliberately unreasonable. Still, most tenure committees do the very same calculations.

The third and last calculations show favor towards candidates with GS education but not because of some fairness or GS quota, but because of the connection between capital and production. These candidates have reached given productivity in spite of the fact that they do not have GN academic capital, therefore - based on this calculation - they have to be promoted against GN educated candidates with the same productivity. The explanation here is the same that this paper has already mentioned: if two candidates have the same amount of production (in our case: the same publication output) then the candidates with less capital perform better. Even a slight weighting could rearrange the ranking of candidates: if one weights $10 \%$ / GS degree, some candidates could go up by 10 positions, and it could grow up to 22 positions with $20 \%$ / GS degree weighting. Note, that these numbers were calculated against the NORM calculation; when we compare the GN 20 ranking with the GS 20 ranking, position changes could go up to 40 places. If the fact that most selection committees use GN-favoring weighting is considered, one could realize that a more just and reasonable calculation which is GSweighted could significantly affect if not subvert the selection process.

One could say, however, that in the case of this last calculation that favors GS education, it is no use being educated at the GN at all - which is absurd. In answer to this posing one could say, on the one hand, that since it is decidedly thought that GN education is a valid academic capital, it is also suggested that GN education would manifest itself in increased publication output if the candidates with this GN education are talented enough. Thus, GS-favored calculation will hit only those GN educated candidates that perform badly despite their extant academic capital, namely, their GN education. On the other hand, the calculations performed in this paper were related to early-career candidates. On later stages of assessment, one could calculate other factors as well, like GN/GS postdoctoral positions, research grants, fellowships or affiliations. Since one could rightfully assume that most successful candidates that apply for positions at GN institutions will have GN capital in form of GN fellowships or affiliations later in their course of a career, their GS-weighted productivity indices will be more balanced because future committees will calculate with their later-stage GN capital. Thus the GSweighted calculation appears to be fair for early career researchers and for their senior peers, too. For early-career researchers, the calculation would balance educational inequalities by overvaluing GS education in case of a great number of publications; and, for senior scholars, these overvaluations of former GS academics will be balanced by the fact that they will get, presumably, GN capital in the form of GN research grants, fellowships, and GN affiliations.

\section{Conclusion}

Despite the assumptions held by most scholars of academic personnel selection, this current analysis has not found any general rule by which GN education necessarily raises science output of GS authors: there were no significant correlations between GN education and the number of Scopus-indexed articles. It is still presupposed, however, that GN academic experience could be considered as a form of academic capital, but this paper proposes that it should be measured on the level of the individual candidates in a form of weighted calculation of their productivity measures. Since GN education is usually considered as an extra value, as an academic surplus, selection committees usually score candidates with GN education with 
extra points. This paper argued that this is a slightly unethical and unreasonable practice since it duplicates the value of GN education. First, it is considered as the extra value in itself, and second, it is incorporated in the raised publication output, too. Moreover, the overvaluation of GN education leads automatically to the undervaluation of GS education which hits most frequently those candidates from the GS. It means that, in the case of equal production, current selection system would decide on the basis of GN/GS education in favor of the GN. It is possible to argue that the underestimation of GS academics on the ground of they are educated at the GS is not less unfair than the underestimation of women or different minority groups by reason of they are who they are. If the global job market in general, and the world of the global academy, in particular, want to act as a field of merit-based work, they should chuck up their preconceptions against GS educated candidates just as they started to abandon the prejudices against women, ethnic groups and LGBTQ people. With this, the global academy might give a good example to other fields of social life like politics, economy, education and any kinds of global collaboration that are subject to international power relations.

This paper maintained the idea that GN education is valuable for GS scholars, not in itself, but because it presumably leads to research excellence that would be manifested in high publication output. Knowing this, one could assume that GN educated candidates would publish less without their GN experience, and GS educated authors would publish more with GN education. This assumption follows directly from the conception of GN education as a source of scientific capital which results in a boosted productivity. Because of the abovementioned considerations, one can conclude that assessments with GN weighting even deepen the gap of inequality and strengthen the bias against GS educated candidates by counting GN capital twice and by adding it to science productivity. As it has been mentioned formerly, in the case of equal production, candidates with less capital (GS education) are more productive than those with more capital (GN education). Therefore, calculation practices that premiate GN education on the level of science output misunderstand the sensible connections between academic capital and productivity.

Of course, this paper does not argue that education, and especially GN education could not be regarded as a value in itself. There is a lot to say about the advantages of GN education. To name a few: students could learn international English, GN standards of research and academic communication, they could participate in GN academic networks and so on. But the question is: how could selection committees measure these values if not in terms of science output? It is not a random fact that university rankings like the Times Higher Education World University Ranking, the QS World University Ranking or the ARWU calculate with the publication output of university or department staffs (and not with their education history). In other words: while GN education could be conceived as a source of many different and important values; in order to be measurable, it should be manifested in measurable variables that is science output.

Hence, the final conclusion is that - as opposed with the most widespread practices - selection committees have better premiate GS educated candidates if they have equal publication output with their GN educated competitors since those GS educated scholars in question made the same production with less capital, so, they are more productive. Since one should not underestimate the role of GN institutions as academic capital, selection committees have good reasons to presume that the productivity of GS authors will further improve after they get a GN affiliation, because this newly gained capital will be added to their already realized productivity measures. By contrast, a similar amount of improvement could not be expected from GN educated candidates since this kind of academic capital has been already incorporated in their current productivity. This present analysis suggests, therefore, that the most rewarding investment for a GN institution is to hire GS educated candidates with very high research output. 


\section{References}

Aksnes, D.W., Rorstad, K., Piro, F.N. \& Siversten, G. (2013). Are mobile researchers more productive and cited than non-mobile researchers? A large-scale study of Norwegian scientists. Research Evaluation, 22(4), 215-223. CrossRef

Asheulova, N. \& Dushina, S. (2014). Research career development in Russia: the role of international mobility In Prpić, I. van der Weijden \& N. Asheulova (2014). (Re)searching scientific careers. St Petersburg: Nestor-Historia, 171-196.

Astaneh, B., \& Masoumi, S. (2017). From paper to practice: Indexing systems and ethical standards. Science and Engineering Ethics, 24(2), 647-654. CrossRef

Altbach, P. G. (2003). The Decline of the Guru. The Academic Profession in the Third World. New York: Palgrave MacMillan.

Altbach, P. G. (2004). Globalisation and the university: Myths and realities in an unequal world. Tertiary Education and Management,10(1), 3-25. CrossRef

Bauder H. 2015. The international migration of academics: a labour market perspective. International Migration, 53, 83-96. CrossRef

Bauder, H., Hannah, C.A. \& Lujan, U. (2017). International Experience in the Academic Field: Knowledge Production, Symbolic Capital, and Mobility Fetishism. Population, Space and Place, 23, 1-13. CrossRef

Behtoui, A. \& Leivestad, J.H. (2019). The "stranger" among Swedish "homo academicus". Higher Education, 77(2), 213-228. CrossRef

Bonitz, M., Bruckner, E. \& Scharnhorst, A. (1997). Characteristics and impact of the Matthew effect for countries. Scientometrics, 40(3), 407-422. CrossRef

Bourdieu, P. (1988). Homo Academicus. Stanford: Stanford University Press.

Bourdieu, P. (1998). Practical Reason. On the Theory of Action. Stanford: Stanford University Press.

Bourdieu, P. (2004). Science of Science and Reflexivity. Cambridge: Polity Press.

Cole, S. \& Cole, J.R. (1967). Scientific output and recognition: A study in the operation of the reward system in science. American Sociological Review, 32(3), 377-390.

Cook, M. (2009). Personnel selection. Adding value through people. Oxford: Wiley-Blackwell.

Demeter, M. (2019). The winner takes it all. International inequality in communication and media studies today. Journalism and Mass Communication Quarterly, 96(1),47-59. CrossRef

Demeter, M. (2018). Nobody notices it? Qualitative inequalities in communication and media research. International Journal of Communication, 12, 1001-1031.

Demeter, M. (2017). The core-periphery problem in communication research: A network analysis of leading publication. Publishing Research Quarterly, 33(4), 402-421. CrossRef

Erren, T.C., Shaw, D.M. \& Morfeld, P. (2016). Analyzing the publish-or-perish paradigm with game theory: The prisoner's dilemma and a possible escape. Science and Engineering Ethics, 22,1431-1446. CrossRef

Evers, A., Anderson, N. \& Voskuijl, O. (2005). The Blackwell handbook of personnel selection. Oxford: Blackwell.

Frankl, R. (2017). Success and luck: good fortune and the myth of meritocracy. Princeton University Press.

Génova, G., Astudillo, H. \& Fraga, A. (2016). The scientometric bubble considered harmful. Science and Engineering Ethics, 22, 227-235. CrossRef

Grenfell, M. (2008). Pierre Bourdieu. Key Concepts. Stocksfield: Acumen Publishing. 
Gumpenberger, C., Sorz, J., Wieland, M. \& Gorraiz, J. (2016). Humanities and social sciences in the bibliometric spotlight. Research output analysis at the University of Vienna and considerations for increasing visibility. Research Evaluation, 25(3), 271-278. CrossRef

Heilbron, J., Sorá, G. \& Boncourt, T. (2018). The social and human sciences in global power relations. London: Palgrave Macmillan.

Hanssen, T.E.S, Jorgensen, F. \& Larsen, B. (2017). The relation between the quality of research, researchers' experience, and their academic environment. Scientometrics 114, 933-950. CrossRef

Herschberg, C., Benschop, I. \& Brink, M. (2018). Selecting early-career researchers: the influence of discourses of internationalisation and excellence on formal and applied selection criteria in academia. Higher Education, 76(5), 807-825. CrossRef

Johnston, L. \& Schluter, P. J. (2017) And the winner is ... : inter-rater reliability among scholarship assessors. Studies in Higher Education, 42(9), 1736-1749. CrossRef

Kaiser, K.A. \& Pratt, T.C. (2016) Crys.al ball or moneyball: does publishing success during graduate school predict career publication productivity? Journal of Crime and Justice, 39(3), 438-454. CrossRef

Kekale, J. (2018). Proactive strategic recruitment in research groups. Tertiary Education and Management, 24(2), 144-153, CrossRef

Lauf, E. (2005). National diversity of major international journals in the field of communication. Journal of Communication, 55(1), 19-151. CrossRef

Lee, J.T. \& Kuzhabekova, A. (2017). Reverse flow in academic mobility from core to periphery: motivations of international faculty working in Kazakhstan. Higher Education, online first article CrossRef

Moody, J. (2004). The structure of a social science collaboration network: Disciplinary cohesion from 1963 to 1999. American Sociological Review, 69(2),213-238. CrossRef

Price, D.J.S. (1965). Networks of scientific papers. Science, 49, 510-515.

Schmitt, N. (2012). The Oxford handbook of personnel assessment and selection. Oxford: Oxford University. Press.

Shen, S., Rousseau, R. \& Wang, D. (2018). Do papers with an institutional e-mail address receive more citations than those with a non-institutional one? Scientometrics, 115(2), 1139-1150. CrossRef

Shenhav, Y. A. (1986). Dependency and compliance in academic research infrastructures. Sociological Perspectives, 29(1), 29-51.

Toth, J. (2012). The dangers of academic bubble economy from a young researcher's perspective. Acta Sociologica, 5(1), 61-67.

Zanotto, S. R., Haeffner, C. \& Guimaraes, J. A. (2016). Unbalanced international collaboration affects adversely the usefulness of countries' scientific output as well as their technological and social impact. Scientometrics, 109, 1789-1814. CrossRef

Zdenek, R. (2018). Editorial board self-publishing rates in Czech economic journals. Science and Engineering Ethics, 24(2), 669-682. CrossRef 